\title{
e-Learning for Fundamental Production Management
}

\author{
Theerapong Maneepen ${ }^{, 1, a^{*}}$ Pensiri Thongtawee ${ }^{, 2, b}$ Jaruwan Junsawat $^{3, \mathrm{c}}$ Run- $^{-}$ \\ grawee Talangaur ${ }^{4, d}$ \\ ${ }^{1,2,3,4}$ Production Technology Education Department, Faculty of Industrial Education \\ and Technology, King Mongkut's University of Technology Thonburi, \\ 126 Pracha-utit Rd., Bangmod, Thungkru, Bangkok, 10140, Thailand \\ a*itheepen@gmail.com, boraemon_lovely_am@hotmail.com, \\ ciam_rungring@hotmail.com, dpalmmy76_67@hotmail.com
}

\begin{abstract}
The purposes this research were to develop content and e-Learning, evaluate efficiency and effectiveness, and assess the satisfaction of e-Learning. This research began analyzed the content into 8 topics; 1) Administration and management of organization, 2) Forecasting and Decision, 3) Capacity Planning, 4) Fundamental production location, 5) Production process layout, 6) Planning and scheduling, 7) Production costs control, 8) Inventory control. the second to design the elearning, the third to develop courseware, the forth to implement, and the fifth to evaluate e-learning. The sampling consisted of KMUTT $4^{\text {rd }}$ year students in Production Technology Education Department to developed the test items and $3^{\text {rd }}$ year students for testing efficiency, and effectiveness, and satisfaction assessment respectively.

The results of e-Learning were as follows: 1) the quality of the content of the e-Learning's lesson is in the good range; (3.92) and of the e-Learning is in the very good range; (4.67). 2) the efficiency of the testing with rated $88.25 / 81.05$ higher than the before standard requirement at $80 / 80,3)$ the $52.11 \%$ effectiveness of learners studying the e-learning is higher at the significance level of 0.05 , and the satisfaction assessment is in the good
\end{abstract}

range; (3.95). The result of the study signifies that e-Learning for Fundamental Production Management developed can be used effectively in e- Learning.

Keywords: e-Learning, online Learning, Fundamental Production Management

\section{Introduction}

The Policy of National Economic and Social Development in Competitive development of the country in The Association of South East Asian Nations: ASEAN; ASEAN Economic Community: AEC in year 2015. Owning to support the growth of economic and production. Government policy has target to hub of ASEAN. Made to the needs manpower, knowledge, technology, and others for increase potential in competitive market's world as WTO especially China, India, and Australia competition and others country in this region and out of region and AEC+3 (China, Japan, and Korea) also.

The production management was a successful of many industry back up that much more important in next day. Because of it mechanism to supports many industry such as automotive industry, electrical industry, an so on. It's necessary to develop this industry and product expansion continuously. For internal and 
external market, manpower capital knowledge skill and competency in learning and develop knowledge for themselves and organization. To sustainable competition, human must increase themselves help level, and more intelligent with simultaneously human and technology development. Advanced information technology and e-Business was the advantage approach.[7]

Because of shortage in human and technology, and others therefore rapid to develop content and pattern in the level of international production equal to other country such as to reduce import either machine tool, and human that effort to reduce unbalance trade of the country.[8] Thus, IT integrated with learning and operation in today. So that e-learning is the one of the tools to improve the competition better in HRM.

\section{Objectives}

This research has objective following:

2.1 To develop e-learning for Fundamental Production Management.

2.2 To determine efficiency, effectiveness, and attitude of e-learning for Fundamental Production Management.

2.3 To assess satisfaction of e-learning Fundamental Production Management.

\section{Benefits}

3.1 To get e-learning for Fundamental Production Management Training and recruit manpower that according to the needs of company.

3.2 To support self-learning and social learning or team working and to help a shortage of teacher, trainer, or coach.[1]

3.3 To introduce the result that apply to general production industry.

\section{Methodology}

This research was steps following [2],[4]:
A) Analysis

1. Created the brainstorm chart

This step was to find out all related topics concerned.

2. Created the concept chart

This step was to rearrange and regroup the related topics that will benefit to created the network analysis chart.

3. Created the network analysis chart

This step was to build the network order of content whereas leaner can be done in series or parallel pattern.

B) Design

4. Created the strategic presentation plan and behavioral objective to course curriculum analysis table

5. Created the module presentation chart

Created the chart for each module according to its importance for best learning effectiveness or achievement.

C) Development of Course

6. Script development

This step was written according to the plan each frame by used of image, color, graphic, video, etc.

7. Storyboard development

The frames of content were reviewed by expert for content correctness. This step was produced the content accuracy and also the validity which represented in terms of appropriateness of content as compared with concept chart according the subject.

8. Development of Test Items

This step was to analyzed the behavioral objective and the contents test items.

D) Development of e-Learning

9. To selected appropriated program

Such as PHP and MySQL program to edit the e-learning.

10. To select and prepare resources

Such as text, graphic, image, video, animation, etc.

11. The correct content and quality test items 
This step was to create e-learning on web-based platform. expert

12. e-Learning checked by media's

Three expert in e-learning or media to checked the quality of e-learning.

E) Evaluation of e-Learning

13. Determine efficiency

To made pilot test with small group representation from the sample.

14. Test efficiency with the sample

E-learning was conducted on thirty $3^{\text {rd }}$ student in Production Technology of Education department, Faculty of Industrial Education and Technology, King Mongkut's University of Technology Thonburi.

The process was followed: pretest, interval test, and posttest. The learning results were evaluated by using test items and attitude evaluation in form of Likert scale (1-5).

\section{Results}

From analysis the result followed: $88.25 / 81.05$ that is above the criterion of 80/80. E-learning effectiveness increased at significance level 0.05 (table 2 the learners have good attitude toward elearning).[6]

Table 1: display the average of marks pretest, interval test, and posttest.

\begin{tabular}{|c|c|c|c|c|}
\hline Test & Students & Mark & Total Mark & $\%$ \\
\hline Pre-test & 30 & 60 & 521 & 28.94 \\
\hline nterval-test & 30 & 60 & 1588.5 & 88.25 \\
\hline Post-test & 30 & 60 & 1459 & 81.05 \\
\hline
\end{tabular}

Table 2: display the average of marks pretest, interval test, and posttest. And difference square between pretest and posttest.

\begin{tabular}{|c|c|c|c|c|c|}
\hline \multirow[b]{2}{*}{ Item } & \multicolumn{2}{|c|}{ Test } & \multirow{2}{*}{$\begin{array}{c}\mathrm{D} \\
=(\text { Post-Pre })\end{array}$} & \multirow[b]{2}{*}{$\mathrm{D}^{2}$} & \multirow[b]{2}{*}{ t-Test } \\
\hline & $\begin{array}{c}\text { Pretest } \\
\text { (D) }\end{array}$ & \begin{tabular}{|c|} 
Post-test \\
(E)
\end{tabular} & & & \\
\hline Total & 521 & 1459 & 938 & 33320 & 5.1387 \\
\hline average & 28.94 & 81.05 & 31.26 & 1110.67 & \\
\hline
\end{tabular}

From table 2 when calculate $\mathrm{D}$ and $\mathrm{D}^{2}$ in formula of t-test for effectiveness of learning. Hypothesis [1],[3]:

$$
\begin{aligned}
& \mathrm{H}: \mu_{1}=\mu_{2} \\
& \mathrm{H}: \mu_{1} \neq \mu_{2}
\end{aligned}
$$

Level of confidential $\alpha=0.05$

$$
\begin{aligned}
& \text { S.D. }=\sqrt{\frac{n \sum d^{2}-\left(\sum d\right)^{2}}{n(n-1)}} \\
& \text { S.D. }=4.09 \\
& \mathrm{t}=\frac{d}{\frac{s}{\sqrt{n}}} \\
& \mathrm{t}=5.1387
\end{aligned}
$$$$
\mathrm{N}=30, \mathrm{~d}=938, \mathrm{~d}^{-}=31.26, \mathrm{~d}^{2}=1110.67
$$

Reliability of learning formula;

$$
\begin{aligned}
& r=(1-\alpha) \times 100 \%, \text { so that } \alpha=0.05 \\
& r=(1-0.05) \times 100 \%, r=95 \%
\end{aligned}
$$

Opened table of critical level of significance $0.05, \mathrm{df}=29$ result that $\mathrm{t}_{0.05}=1.699$ so that $\mathrm{t}=5.1387>1.699=\mathrm{t}_{(0.05,29)}$ so that eject $\mathrm{H}_{0}$ accept $\mathrm{H}_{1}$ mean as result of both test have difference confidential at $95 \%$.

5.1 e-Learning development for Fundamental Production Management consist of 8 fundamental contents: 1) Administration and management of organization, 2) Forecasting and Decision, 3) Capacity Planning, 4) Fundamental production location, 5) Production process layout, 6) Planning and scheduling, 7) Production costs control, 8) Inventory control.

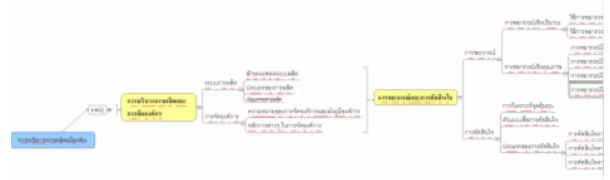

Fig. 1: display Concept chart and Content Network Analysis by MindMap

5.2 After building test items; were done to find difficulty and discrimination. From analysis the results and got 60 test items pass criterion. 


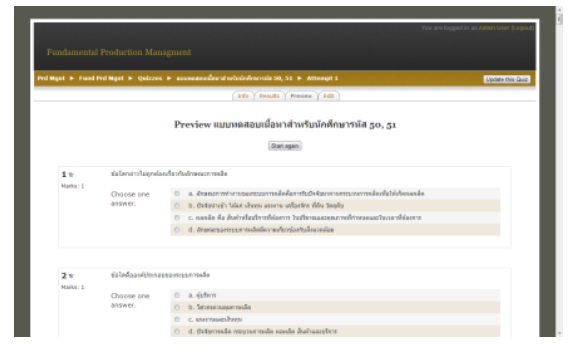

Fig. 2: Test items development

5.3 Results from expert in quality revealed that e-Learning package for Fundamental Production Management was showed quality of learning content, media, and user's satisfaction of package in good level at mean of $3.92,4.67$, and 3.95 , respectively.

5.4 e-Learning from development shown in figure 3

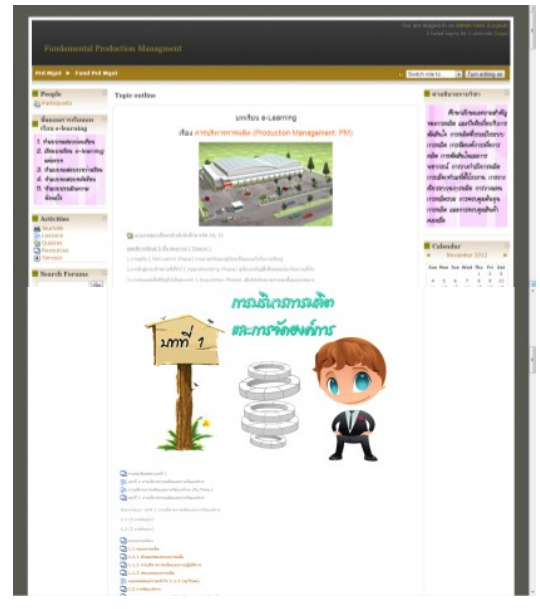

Fig. 3: e-Learning Screen

5.5 The efficiency result of e-learning package was showed at $88.25 / 81.05$, which was higher than the standard requirement set at 80/80.

5.6 Finally, the result of effectiveness of learners studied the e-learning was showed at $52.11 \%$, which was significantly different at the level of 0.05 . The t-test result of both test have difference confidential at $95 \%$.

\section{Conclusion}

Conclusion of research followed:

The efficiency result of e-learning package was showed at 88.25/81.05, which was higher than the standard requirement set at 80/80. Finally, the result of effectiveness of learners studied the e-learning was showed at $52.11 \%$, which was significantly different at the level of 0.05 . This would be concluded that e-learning for Fundamental Production Management package could be used for online learning by self-study with individualized leaner.

\section{References}

[1] K. Teankunted, "Principle of Analysis and Evaluation in Education", Bangkok: KMITT, 1993.

[2] P. Tirathanagul, et al., "Process for Developing Interactive Multimedia CAI Package", Industrial Education Journal, Vol. 1, No. 2, pp. 14-18, 1998.

[3] Kanda Poonlaptawee, (1996), "Statistic for Research", Bangkok: Physic Center, 1996.

[4] P. Tirathanagul, et al., "Technique to Self-learning for Distance Education online", Bangkok: Bangkok Software Technology House, 2011.

[5] Academic Department, "Production Management", Bangkok: Sukhothai Thammathirat Open University, 1994.

[6]Thanomporn Laohajaratsang, "Designing e-Learning", Bangkok: Aroon Karnpim, 2002.

[7] Chumpol Saringkarnsiri, "Production Planning and Control", Bangkok: Thai-Japan Association, 2002.

[8] Richart J. Hopeman, "Production: Concept, Analysis Control", $3^{\text {rd }}$ Edition, Ohio: Charles E.Merrill, 1976. 